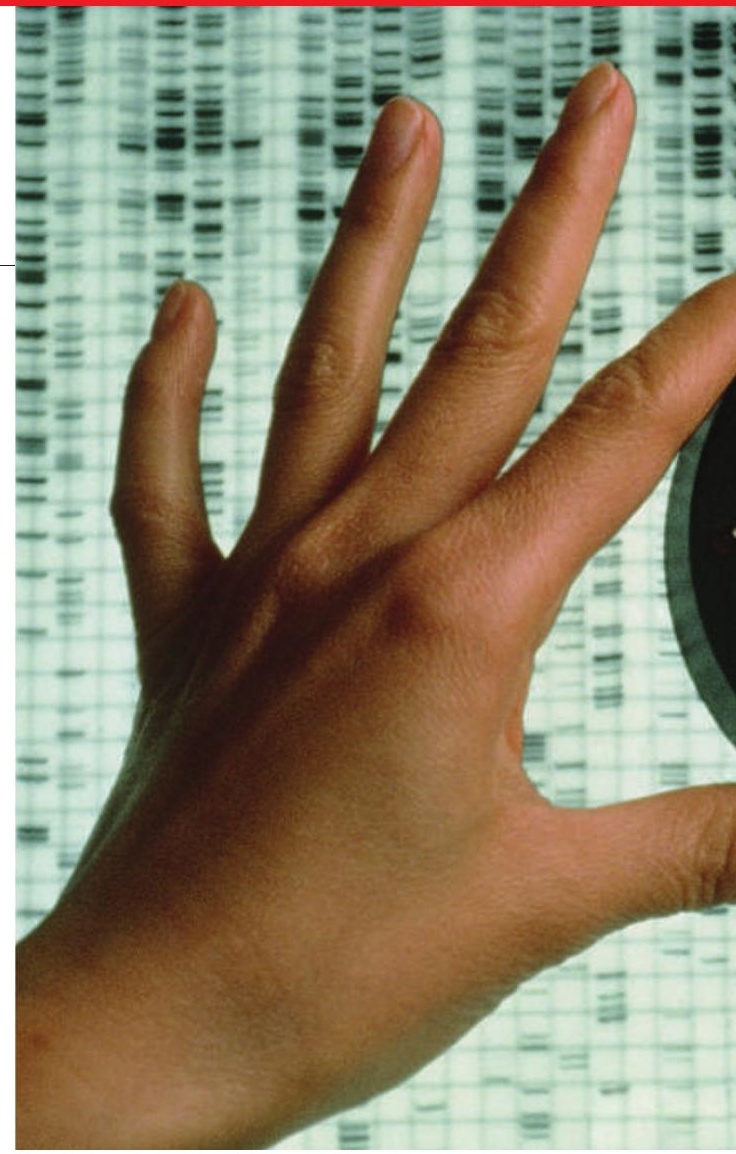

Nature doi:10.1038/nature05616; 2007) suggest that the GWA approach will bear fruit, and lots of it. The group, led by Constantin Polychronakos of McGill University in Quebec, Canada, studied some 393,000 single nucleotide polymorphisms in the genomes of around 700 patients with type 2 diabetes, and 600 controls; the findings were then confirmed in another 14,000 people. The researchers identified four genomic regions that confer a significant risk

\title{
Berkeley's energy deal with BP sparks unease
}

\section{SAN DIEGO}

Debate is intensifying at the

University of California, Berkeley, over a $\$ 500$-million energy research partnership with $B P$. The energy company announced on 1 February that it will fund a decade of alternative-energy research by Berkeley and its partners. But concerns are spreading across the campus about the propriety of the industrial relationship.

Some fear that the pact - for which final details are still being worked out - could be a repeat of a controversial \$25-million contract that the university entered into in 1998 with the biotech giant Novartis (see Nature 399, 5; 1999). That deal expired in 2003, amid criticism that the academic freedom of some university researchers had been compromised (see Nature 426, 591-594; 2003).

Berkeley and its partners, the Lawrence Berkeley National Laboratory (LBNL) and the University of Illinois at UrbanaChampaign, beat four other universities in a six-week competition for cash from the

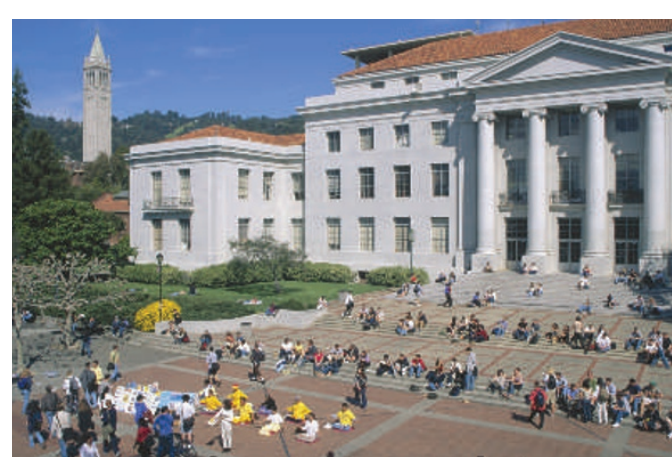

energy company. The research agenda for the initiative has been drawn up by a group of Berkeley researchers. It aims to use biotechnology to develop new energy sources, for example genetically modifying plants for use as fuels, and using enzymes to convert plant material into fuel

The University of California, Berkeley, is to be home to an energy research centre in a partnership with BP. more efficiently, as well as studying how these new methods might affect agriculture and society.

During forthcoming budget negotiations, California's governor Arnold Schwarzenegger plans to push the state for $\$ 40$ million in bonds to pay for a new building called the Energy Biosciences Institute, where BP-funded researchers would work. The building would house university professors and students, along with perhaps 50 industry scientists.

Industry funds a lot of research on public and private university campuses, and it's fairly common for companies to have labs located near institutes where industry and academic researchers work together - as Intel and Yahoo do at Berkeley, for example. But it's rare 
